\title{
Radiofrequency electromagnetic radiation-induced behavioral changes and their possible basis
}

\author{
Sareesh Naduvil Narayanan ${ }^{1}$ (D) $\cdot$ Raghu Jetti $^{2} \cdot$ Kavindra Kumar Kesari $^{3} \cdot$ Raju Suresh Kumar $^{4} \cdot$ Satheesha B. Nayak $^{5}$. \\ P. Gopalakrishna Bhat ${ }^{6}$
}

Received: 11 May 2019 / Accepted: 16 August 2019 / Published online: 28 August 2019

(C) Springer-Verlag GmbH Germany, part of Springer Nature 2019

\begin{abstract}
The primary objective of mobile phone technology is to achieve communication with any person at any place and time. In the modern era, it is impossible to ignore the usefulness of mobile phone technology in cases of emergency as many lives have been saved. However, the biological effects they may have on humans and other animals have been largely ignored and not been evaluated comprehensively. One of the reasons for this is the speedy uncontrollable growth of this technology which has surpassed our researching ability. Initiated with the first generation, the mobile telephony currently reaches to its fifth generation without being screened extensively for any biological effects that they may have on humans or on other animals. Mounting evidences suggest possible non-thermal biological effects of radiofrequency electromagnetic radiation (RF-EMR) on brain and behavior. Behavioral studies have particularly concentrated on the effects of RF-EMR on learning, memory, anxiety, and locomotion. The literature analysis on behavioral effects of RF-EMR demonstrates complex picture with conflicting observations. Nonetheless, numerous reports suggest a possible behavioral effect of RF-EMR. The scientific findings about this issue are presented in the current review. The possible neural and molecular mechanisms for the behavioral effects have been proposed in the light of available evidences from the literature.
\end{abstract}

Keywords Mobile phone $\cdot$ Radiofrequency electromagnetic radiation $\cdot$ Brain $\cdot$ Behavior $\cdot$ Anxiety $\cdot$ Locomotion $\cdot$ Learning and memory $\cdot$ Blood-brain barrier

Responsible editor: Philippe Garrigues

Sareesh Naduvil Narayanan

sareeshnn@yahoo.co.in; sareesh@rakmhsu.ac.ae

1 Department of Physiology, RAK College of Medical Sciences, RAK Medical \& Health Sciences University, PO Box 11172, Ras Al Khaimah, UAE

2 Department of Basic Medical Sciences, College of Applied Medical Sciences, King Khalid University, Abha, Kingdom of Saudi Arabia

3 Department of Applied Physics, Aalto University, Espoo, Finland

4 Department of Basic Sciences, College of Science and Health Professions-Jeddah, King Saud Bin Abdulaziz University for Health Sciences, National Guard Health Affairs, P. O. Box 9515, Jeddah 21423, Kingdom of Saudi Arabia

5 Department of Anatomy, Melaka Manipal Medical College (Manipal Campus), Manipal Academy of Higher Education, Manipal 576104, India

6 Division of Biotechnology, School of Life Sciences, Manipal Academy of Higher Education, Manipal 576 104, India

\section{Introduction}

Radiation is generally described as the transmission of energy through space in the form of waves or particles. Electromagnetic radiation (EMR) is a type of radiation, wherein the waves of electric and magnetic energy move together through the space (Cleveland and Ulcek 1999). According to Cleveland and Ulcek (1999), the energy of radiofrequency (RF) electromagnetic waves is not sufficient to cause ionization of atoms and molecules; hence, RF energy is said to be non-ionizing radiation. Though the aforesaid fact is true and well known to everyone, the relationship between this radiation and body systems is still a major concern. The very reason for this is the uncontrollable growth of mobile phone subscribers and the mobile phone use as this technology uses RF-EMR for data transfer. While communicating with a person, it is important to consider the possible health hazards due to technological advances. Until today, the scientific community could not categorically say whether these radiations are hazardous to humans. At the 
same time, they could not either rule out the possible health effects of these radiations. At present, we adopt a precautionary policy (WHO 2000) while dealing with these radiations. Adding more complexity to the situation, in 2011, the International Agency for Research on Cancer (IARC) of World Health Organization (WHO 2011) has classified RF-EMR emitting from mobile phones to be carcinogenic (group 2B) to humans (IARC 2011). The effects of these radiations on body systems might depend on the frequency and power of radiation. In case of lower frequencies of RFEMR, the damage caused to the cells is determined mainly by heating effects, and thus by the radiation power. SAR is a measure of the rate at which energy is absorbed by the human body when exposed to RF-EMR. It is defined as the power absorbed per mass of tissue and has units of watts per kilogram $(\mathrm{W} / \mathrm{kg})$. SAR is usually averaged either over the whole body or over a small sample volume (typically $1 \mathrm{~g}$ or $10 \mathrm{~g}$ of tissue). The value cited is then the maximum level measured in the body part studied over the stated volume or mass. SAR values for mobile phones always refer to the maximum possible transmission power. SAR provides a straightforward means for measuring the RF-EMR exposure characteristics of cell phones to ensure that they are within the safety guidelines set by the regulatory bodies of different countries. Although the Federal Communications Commission (FCC) limit for public exposure from cellular telephones is a SAR level of 1.6 watts per kilogram $(1.6 \mathrm{~W} /$ $\mathrm{kg}$ ), this value considerably varies depending on each country's regulatory bodies.

Currently, the effect of RF-EMR on humans and various other organisms is a topic of interest. Work has been extensively carried out to understand the effects of RF-EMR in single-celled organisms (Aksoy et al. 2005; Gos et al. 2000; Markkanen et al. 2004), lower model organisms (Cammaerts 2013; Chavdoula et al. 2010), in rodents (Ahmadi et al. 2018; Mokarram et al. 2017; Sienkiewicz and van Rongen 2019), and in humans (Lai 2014; Carlberg and Hardell 2017; Henz et al. 2018; Elsawy et al. 2019). Behavior is defined as the way in which an organism reacts or acts. The surroundings have great influence on behavior of the organism. A good environment is a must for normal development; a bad physical environment can adversely affect the behavior of the organism to a great extent. Attempts have been made to evaluate the RF-EMR-induced behavioral effects on various animal models and on humans. Although several reports suggest the possibility of behavioral effects of RF-EMR, several contradictory observations can be seen in many of the published reports. The objective of the current review is to evaluate the behavioral effects of RF-EMR particularly on learning, memory, anxiety, and locomotion reported in rodents. In addition, an attempt has been made to explain the possible mechanisms that attribute to these behavioral changes.

\section{Methods}

Major electronic data bases such as MEDLINE/PubMed were the primary databases selected for the search of published literatures. Key words like "mobile phone radiation" and "anxiety"/"learning memory"/"locomotion", mobile phone radiation, and "hippocampus"/“"blood brain barrier"/“cortex"/ "cerebellum"/“amygdala" were used to extract relevant literatures. Several publicly available sources from regulatory authorities like WHO, IARC were also referred if they contain information pertaining to biological effects of RF-EMR. All titles and abstracts identified via PubMed search relevant to the issue of current review were vetted. Those publications, which did not relate to the specific topic of current review, were excluded at this stage itself. Each and every article that discussed any behavioral, histological, or biochemical endpoints in rats/mice were retained. Articles that discussed RFEMR effects in humans and in other lower model organisms (other than rats/mice) were excluded. Those articles in nonEnglish were also excluded. All selected articles were those deemed to support the issue of current review. Those articles met the inclusion criteria for further review were carefully analyzed. The parameters, such as RF-EMR frequency, specific absorption rate-SAR, exposure set-up, nature of exposure and duration of exposure, and all relevant biological effects, particularly the neurobehavioral effects were extracted from each one of them and summarized. Those researches reporting behavioral effects of RF-EMR published nearly past 10 years have used in this review as they provide the latest data about the radiation effects. However, some articles which were published earlier than this were also included according to their relevance to this review.

\section{Behavioral effects of RF-EMR}

\section{RF-EMR on learning and memory}

Many research reports have been published about the effect of RF-EMR on cognition. But the results have been inconsistent (Fragopoulou and Margaritis 2010). Bouji et al. (2016) have exposed 22-24-month aged male rats to $900 \mathrm{MHz}$ RF-EMR, for 1 month. They have found that RF-EMR did not induce specific cerebral functional vulnerability (in spatial, emotional memory, anxiety, and locomotor activity) to RF-EMR during senescence. Intrauterine exposure to the GSM field did not show any cognitive deficits in the offspring of RF-EMRexposed pregnant rats when tested for operant-behavior (Bornhausen and Scheingraber 2000). Differently, Aldad et al. (2012) reported that $800-1900 \mathrm{MHz}(\mathrm{SAR} 1.6 \mathrm{~W} / \mathrm{kg}$ ) mobile phone exposure (phone on active call mode for $24 \mathrm{~h}$ per day throughout gestation; days 1-17) induced memory impairment, hyperactivity-like behavior in mice exposed to 
RF-EMR in-utero. In a study by Nittby et al. (2008), exposure for 55 weeks induced some memory deficits in rats for objects and their temporal order of presentation. Nonetheless, detecting the place and exploratory behaviors was not affected.

In another study, a single 45-min exposure to $900 \mathrm{MHz}$ radiation had induced an elevation in 5-HT level without changing blood glutamate level of rats. Increased 5-HT level might lead to learning impairment and spatial memory deficit (Eris et al. 2015). In the study by Tang et al. (2015), exposure to $900 \mathrm{MHz}$ radiation had altered the neurobehavioral performance in rats. These changes were more explicit in 28-day exposed group as demonstrated by impaired spatial memory and damaged blood-brain barrier (BBB) permeability by activating the mkp-1/ERK pathway (Tang et al. 2015). Studies have also proven that exposure to $900 \mathrm{MHz}$ radiation can also alter the spatial learning and reference memory and induce morphological changes in the hippocampus CA1 region $(\mathrm{Li}$ et al. 2012). Reports also indicate that, chronic mobile phone radiation exposure could severely interact with the consolidation phase of recognition memory in mice and it is postulated that this may be due to the effect of RF-EMR on information transfer pathway connecting the entorhinal and parahippocampal regions as they are involved in the object recognition memory task (Ntzouni et al. 2011). On the other hand, in the experiments conducted by Daniels et al. (2009), RF-EMR exposure in rats did not induce any significant changes in spatial learning and memory. However, they observed decreased locomotor activity and increased grooming tendency in RF-EMR-exposed rats. In the studies conducted by Ammari et al. (2008a, b), chronic head only exposure to $900 \mathrm{MHz}$ radiation for 8 or 24 weeks did not alter the spatial learning and memory in an eight arm radial maze test. In contrary to this, Narayanan et al. (2015) have reported that 1-month exposure to RF-EMR (900 MHz) could alter the Morris water maze performance and induced dendritic changes in rat hippocampus.

According to the reports by Kumlin et al. (2007), exposure to $900 \mathrm{MHz}$ radiation can enhance spatial memory performance without affecting morphology of hippocampal morphology in rats. In a study on mice, by Fragopoulou et al. (2010), 2-h exposure to $900 \mathrm{MHz}$ radiation on a daily basis had induced alterations in spatial memory performance. Another study suggests that a single exposure to $900 \mathrm{MHz}$ radiation does not induce activation of astrocyte but increased IL- $1 \beta$ in the olfactory bulb and leads to enhance contextual emotional memory in middle-aged rats (Bouji et al. 2012). In contrast to this, another report suggests that $916 \mathrm{MHz}, 10 \mathrm{w} /$ $\mathrm{m}^{2}$ EMF could change the learning and memory in rats to some extent in a short period during exposure; however, the rats get adapted to long-term exposures (Hao et al. 2013). In another study, RF-EMR exposure for a period of 4 weeks had induced deficits in spatial memory performance (Narayanan et al. 2009). In yet another recent study (Saikhedkar et al.
2014), exposure to $900 \mathrm{MHz}$ for $4 \mathrm{~h}$ /day for a period of 15 days had induced deficits in learning and memory. There was also hippocampal neuronal degeneration in these rats. Conflicting reports are available on the effect of RF-EMR on emotional learning and memory. When pregnant rats were exposed to RF-EMR throughout their gestational period (900 MHz), the emotional learning and behavior in their male and female offspring were found to be drastically affected by the exposure as demonstrated by their altered learning acquisition and memory retention (Razavinasab et al. 2016). Report also suggests that RF-EMR did not induce changes in passive avoidance behavior in mid and late adolescent rats (Keleș et al. 2018). One-month exposure to $900 \mathrm{MHz}$ RF-EMR induced altered passive avoidance behavior and morphological changes in the hippocampus of rats (Narayanan et al. 2010). Further, a study investigated to know whether RF-EMR induce molecular changes in amyloid precursor protein processing and amyloid beta $(A \beta)$-related memory impairment in the $5 x F A D$ mouse, revealed no effect on $A \beta$-related memory impairment or $A \beta$ accumulation in the $5 x F A D$ Alzheimer's disease model (Son et al. 2016). In a recent report, Wang et al. (2017) demonstrated that exposure to $1800 \mathrm{MHz}$ RF-EMR can significantly increase recognition memory in mice and can change dendritic-spine morphology and neuronal excitability in the hippocampus and prefrontal cortex. In another very recent study, Ahmadi et al. (2018) report that 4 weeks of mobile phone exposure impaired inhibitory avoidance (IA) memory performance in rats.

\section{RF-EMR on anxiety}

Anxiety can be defined as an emotional and physiological response that can influence humans as well as animals, which could be associated with a threat to their well-being (Steimer 2002). Anxiety-like behavior in animal models is often extrapolated to the anxieties that are reported in human beings. It is considered as a pliable response to a foreign environment, chiefly when the individual is exposed to any alarming situation or threat (Ohl 2005). Many studies indicate the widespread usage of mobile phones as a proven potential risk factor to human health in this era of technology boom. For investigating anxiety-like behavior in animal models over the years, researchers have developed various behavioral paradigms. Some of the commonly used strategies in testing anxiety in animal models includes elevated plus maze (EPM), open field test (OFT), and black and white box. Studies by Zhang et al. (2017), in RF-EMR-exposed mice brain, revealed significant reduction in GABA and aspartic acid (Asp) in cortex and hippocampus. The authors claim that the possible cause of anxiety in RF-EMR-exposed rat brain could be due to the reduction in GABA and Asp. Open field test, in RFEMR-exposed mice, revealed a significant reduction in the time spent and distance traveled in the central arena in 
comparison with the sham group. This is considered as a behavioral indicator of elevated anxiety levels. Researchers have also reported the potential impact of RF-EMR exposure on increasing the emotionality of rodents. This was demonstrated by the exposed groups decreased open arm entries, time spent, and total distance traveled on the open arms (Narayanan et al. 2013). Similar findings were also reported by Saikhedkar et al. (2014). They noticed that the rats presented significant anxiety-like behavior in EPM and OFT when exposed to $900 \mathrm{MHz}$ RF field for about 15 days. In a study conducted by Zhang et al. (2017), when mice were exposed to a radiofrequency field of $1.8 \mathrm{GHz}$ for 4 weeks, induced anxiety-like behavior in the exposed animals. This was demonstrated by their decreased total accumulative distance traveled and time spent in the center area of open field. However, in contrast to this, Junior et al. (2014) found no significant effects on the anxiety-like behavior in male rats that were exposed to RFEMR. Obajuluwa et al. (2017) investigated the impact of 4- to 8-week exposure of $2.5 \mathrm{GHz}$ band radio-frequency electromagnetic wave on male rats. They found that there was increased anxiety-like behavior which was evidenced by reduction in the line crossing frequency in OFT. In a study by Narayanan et al. (2013), cell phone radiation-exposed rats showed low rearing and high grooming frequency in EPM test. This correlates positively with the enhanced anxietylike behavior. In another study, similar behavioral pattern was noticed when animals were subjected to 10-min call per day for 4 weeks (Shehu et al. 2016). Rats exposed to 50 missed calls per day for 4 weeks from cell phone kept in a vibratory mode showed hypoactivity in EPM test (Kumar et al. 2009). This finding was supported by a later study by Saikhedkar et al. (2014). They found that when rats were subjected to mobile phone radiations for about half a month ( $4 \mathrm{~h}$ per day), the exposed group exhibited enhanced anxiety in EPM test. Mobile phone radiation of $900 \mathrm{MHz}$ for $1 \mathrm{~h} /$ day has also induced significant changes in place preference behavior (Narayanan et al. 2018). Additionally, Sokolovic et al. (2012) have reported that GSM mobile phone exposure $900 \mathrm{MHz}$ for $4 \mathrm{~h} /$ day induced anxiety-related behavior after 10 days of exposure. The observed changes were the most intense after 60 days of exposure.

\section{RF-EMR on locomotor behavior}

Many researchers have reported the effects of RF-EMR on locomotor behavior in animals. According to some of these studies, RF-EMR does not alter the locomotion. But some researchers have shown positive correlation between cell phone radiation and locomotor behavior in rodents (Odac1 et al. 2013; Kim et al. 2017). Decreased locomotor activity was observed in rats when exposed to mobile phone radiation (4 h/day) for 15 days (Saikhedkar et al. 2014). Obajuluwa et al. (2017) reported that exposure to $2.5 \mathrm{GHz}$ radiations for
4 to 8 weeks of duration reduced locomotor activity in rats indicated by reduced line crossing frequency pattern in open field test. In the meantime, a report by Narayanan et al. (2013) demonstrated that mobile phone radiation over a period of 1 month did not significantly alter the general locomotion in rats.

\section{Possible underlying mechanisms for RF-EMR-induced behavioral changes}

It is evident from the Table 1 that a substantial number of reports are available indicating the possible behavioral effects of RF-EMR. Although $900 \mathrm{MHz}$ frequency band has been studied extensively, behavioral effects induced by other frequency bands have also been reported by many (Table 1). What could be the possible reason for the altered behavioral patterns seen in rodents following radiation exposure? The possible reasons for the altered behavioral patterns observed after RF-EMR exposure could be (a) the structural changes that may occur in various brain regions (blood-brain barrier, hippocampal formation, cerebral cortex, cerebellum, and amygdala), (b) impact of RF-EMR effects on glial cells, and/ or (c) the modulatory role of RF-EMR on various neurotransmitter levels in different brain regions.

\section{Structural changes in the brain after RF-EMR exposure}

\section{Altered blood-brain barrier (BBB) integrity}

This has been extensively studied for several decades. Rats subjected to $915 \mathrm{MHz}$ continuous and pulse modulated $(8,16$, 50 , and $200 \mathrm{~s}^{-1}$ ) wave electromagnetic radiation, with 0.016 to $5 \mathrm{~W} / \mathrm{kg}$ SAR for $2 \mathrm{~h}$, have showed presence of albumin and fibrinogen. This confirms that there was altered structural integrity of BBB following electromagnetic radiation exposure (Salford et al. 1994). Single 20-min exposure to $1.3 \mathrm{GHz}$ continuous or pulsed microwave energy can also result in an increase in permeability of BBB in medulla, cerebellum, hypothalamus, hippocampus, and cortex. In one of the studies, permeability had increased immediately following the exposure and had lasted for $4 \mathrm{~h}$ (Oscar and Hawkin 1977). In a study, continuous wave radio frequency radiation (RFR) exposure had significantly increased the permeability of BBB in male animals. However, this effect was not observed in female animals (Sirav and Seyhan 2009). Blood-brain barrier is usually low permeable to hydrophilic and charged molecules; an increased permeability for these molecules is detrimental to the brain. Exposure to EMF enhances the permeability of BBB for macromolecules; however, this process is reversible (Stam 2010). In addition to that, $2 \mathrm{~h}$ of exposure to EMR (electromagnetic radiation) emitted from GSM mobile phone resulted in albumin extravasation into the neural tissue and 


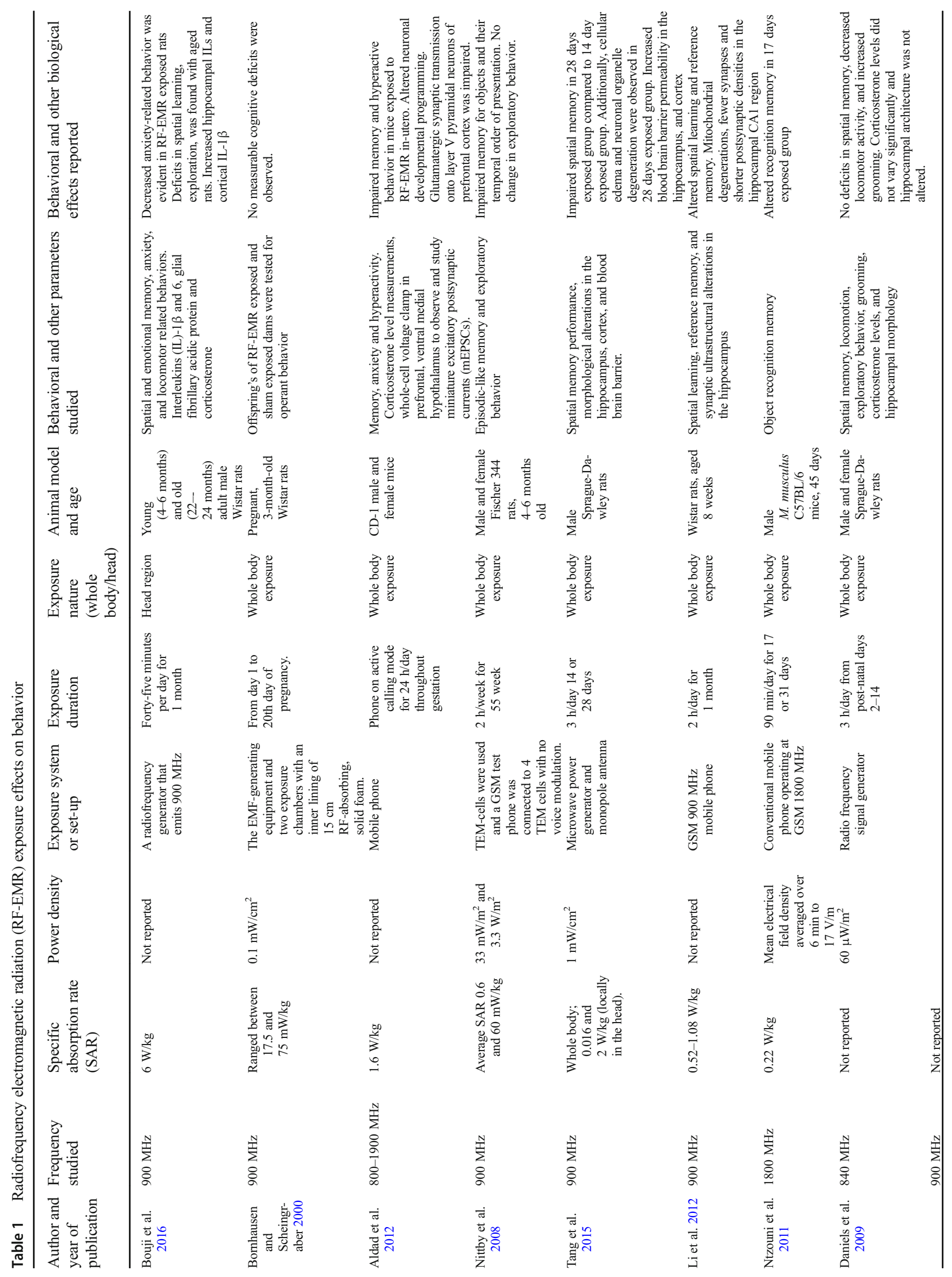




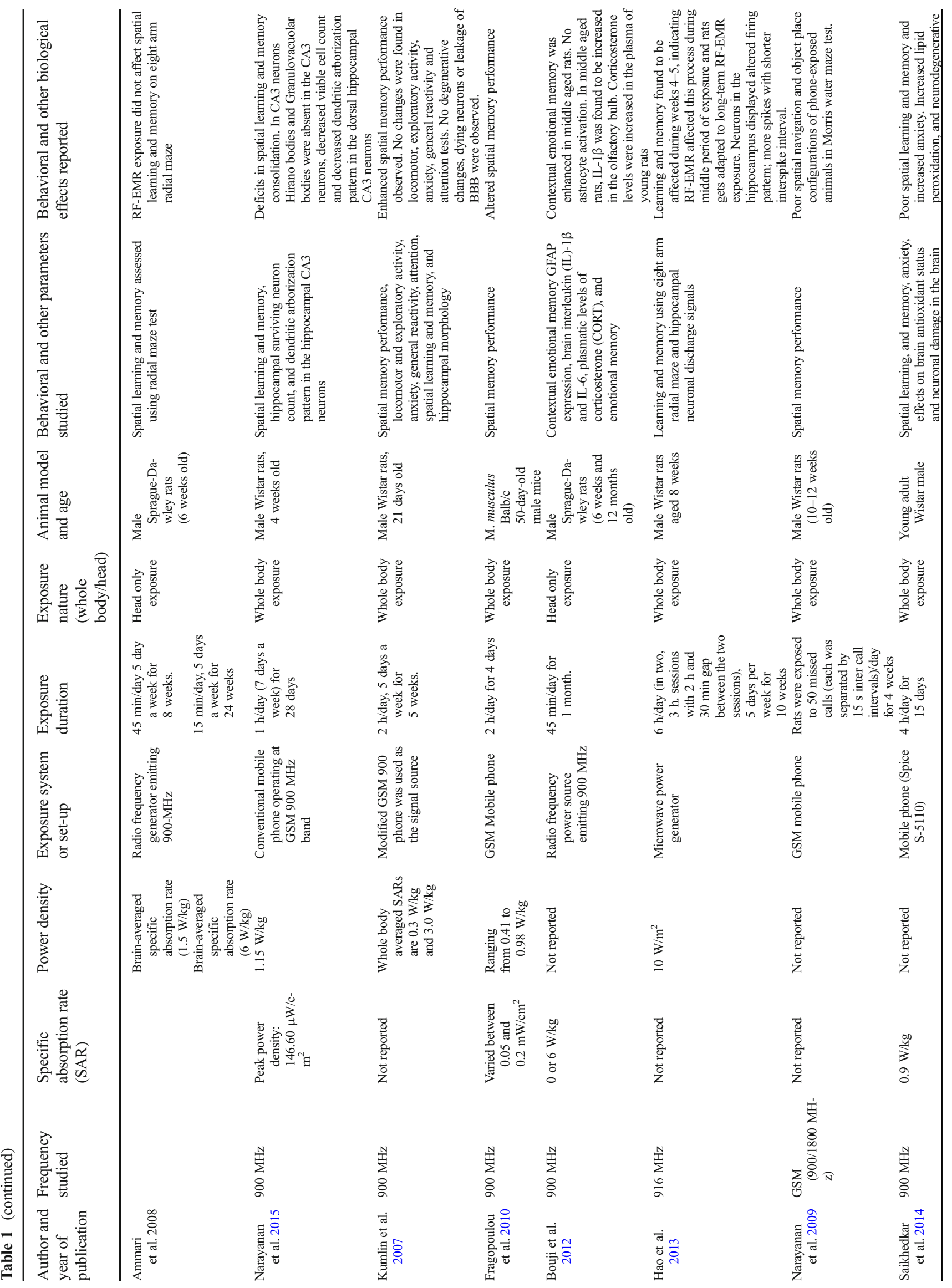




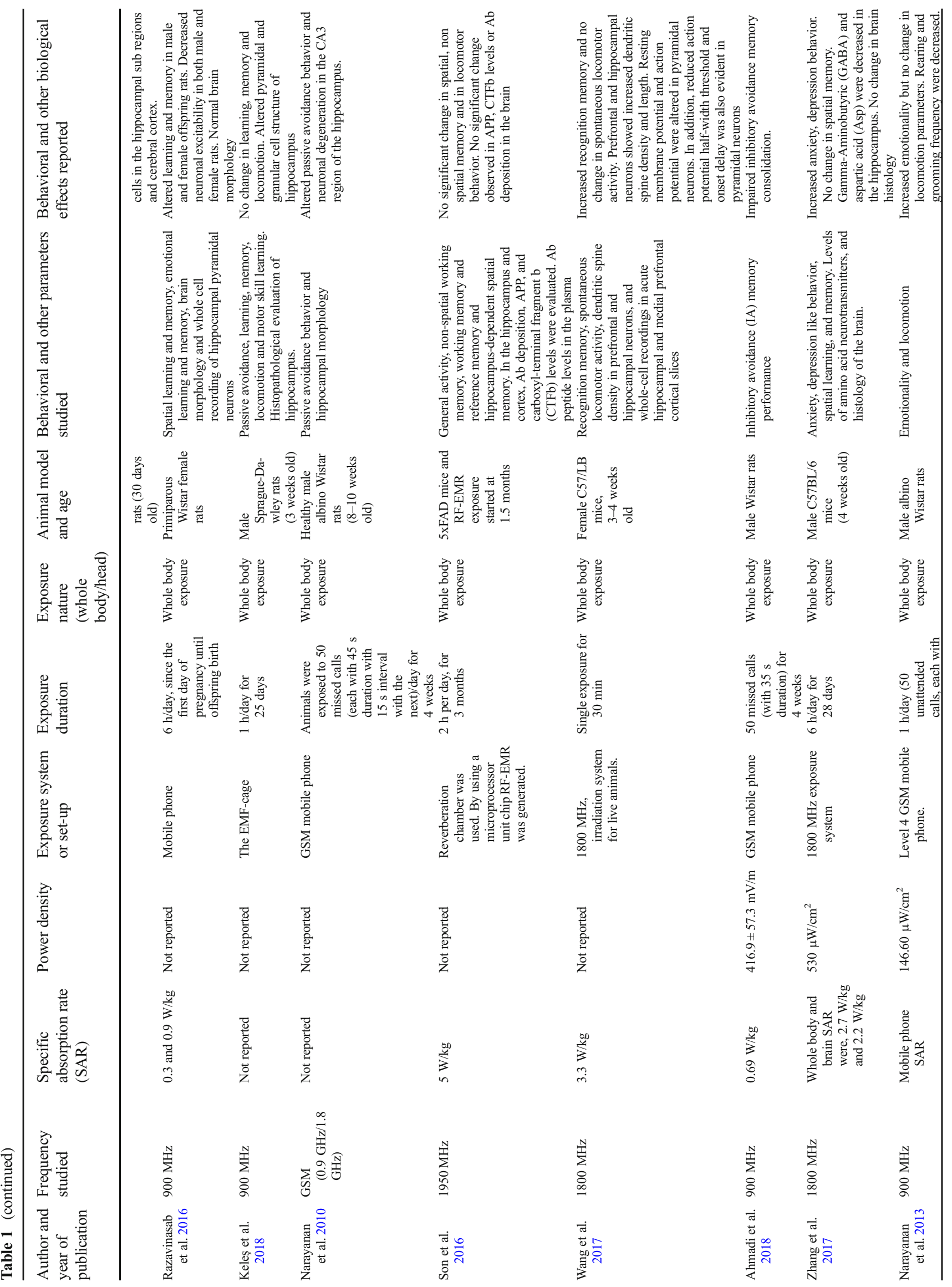




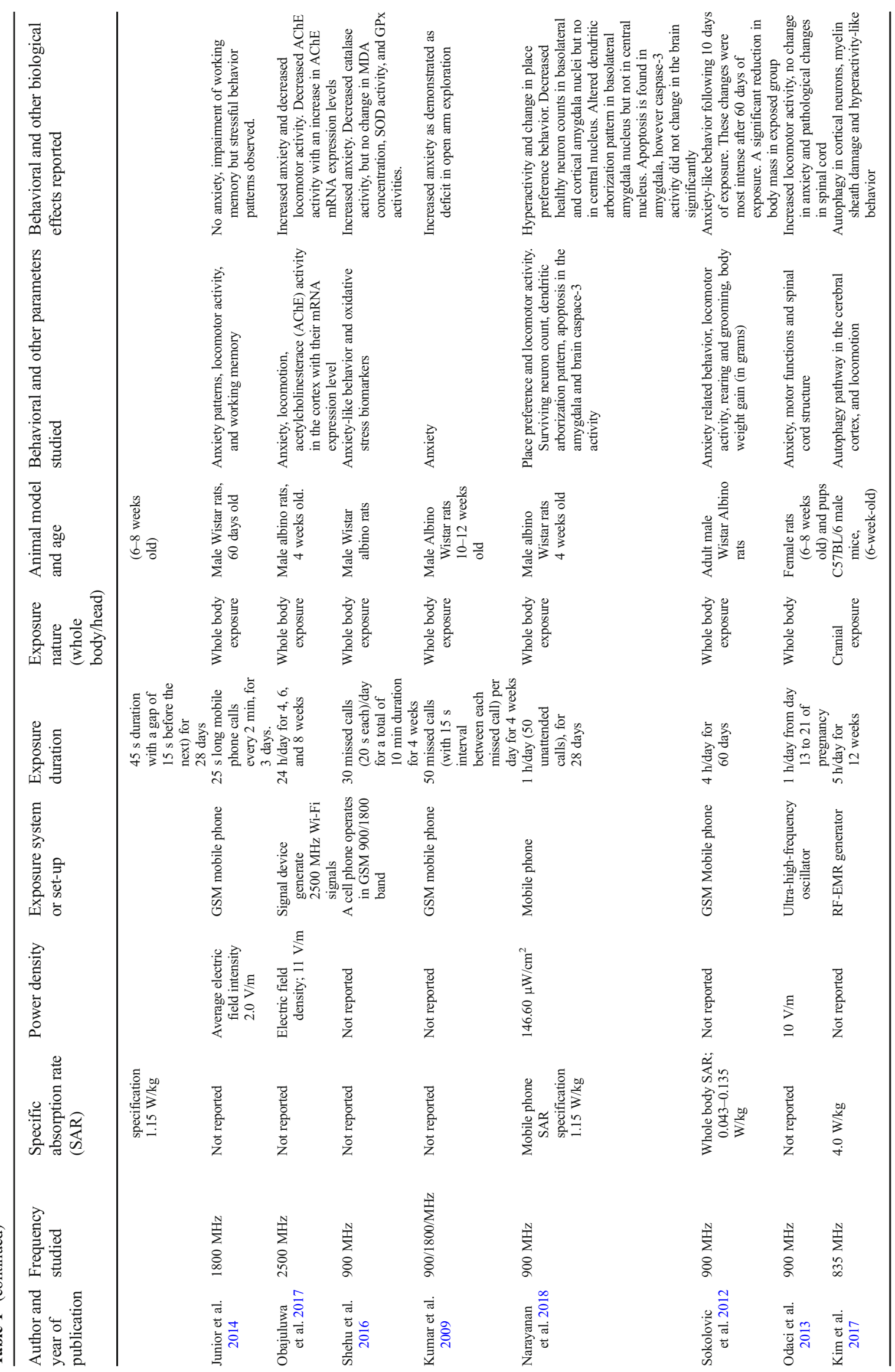


lead to neurodegeneration. Increased BBB permeability was noted immediately after the exposure and lasted for 14 days (Nittby et al. 2009). Further, in one of the studies, exposure to $900 \mathrm{MHz}$ radiation for $3 \mathrm{~h} /$ day for 14 or 28 days at SAR between 0.016 and $2 \mathrm{~W} / \mathrm{kg}$ locally in the head caused albumin extravasation in hippocampus and cortex resulting from damage to BBB. Cellular edema and cell organelle degeneration were noted in 28-day exposure group. These structural changes produced significant impairment in spatial memory (Tang et al. 2015). GSM microwave exposure for $2 \mathrm{~h} /$ day at $900 \mathrm{MHz}$ with SAR of $0.12,1.2,12$, or $120 \mathrm{~mW} / \mathrm{kg}$ for either 14 or 28 days. Albumin extravasation and its uptake into neurons were increased in 14-day exposure group. Numbers of dark neurons were enhanced in 28-day group (Eberhardt et al. 2008), whereas $1439 \mathrm{MHz}$ EMF near field exposure with SAR of 0,2 , and $6 \mathrm{~W} / \mathrm{kg}$ for $90 \mathrm{~min} /$ day for 1 or 2 weeks did not show any pathological changes and vascular permeability of BBB in immature and young rats (Kuribayashi et al. 2005). Exposure to $1457 \mathrm{MHz}$ RFR for $50 \mathrm{~min}$ did not show evidence of albumin leakage. This proves that there were no changes in the BBB permeability among rats of different age groups (Masuda et al. 2015).

\section{Changes in the cytoarchitecture of hippocampal formation}

There is enough scientific evidence for electromagnetic radiation causing significant neurodegeneration in brains, especially basal nuclei and hippocampus (Salford et al. 2003). Maskey et al. (2010a) exposed the rats to $835 \mathrm{MHz}$ EMF with SAR of $1.6 \mathrm{~W} / \mathrm{kg}$ and $4.0 \mathrm{~W} / \mathrm{kg}$ for $1 \mathrm{~h} /$ day for 5 days: 1 day and for 1 month. This exposure for 1 month produced neurodegeneration in CA1 are of hippocampus indicating a possible detrimental effect on hippocampal functions. In a report by Altun et al. (2017), exposure to EMF for $1 \mathrm{~h}$ /day for 15 days showed significant neuronal loss in CA1 and CA2 areas; however, there was no significant difference in CA3 area of hippocampus. Loss of granule cells was noted in the dentate gyrus. Further, significant short entrance latency was observed in EMF-exposed group (Altun et al. 2017). However, exposure to GSM radiation for $1 \mathrm{~h} /$ day for 4 weeks in mobile phone-exposed animals resulted significant histopathological changes in hippocampal CA3 region and short entrance latency into the dark compartment (Narayanan et al. 2010). Animals that received $900 \mathrm{MHz}$ radiation through mobile phone for $4 \mathrm{~h}$ /day for a period of 15 days have shown neurodegeneration in CA1, CA3, and dentate gyrus sub regions of hippocampus. This neuronal loss could be a reason for poor learning and memory (Saikhedkar et al. 2014). In another study, when pregnant mice from 0.25 and 11.25 days of gestation to till term received $10 \mathrm{GHz}$ microwave radiation exposure, their offspring mice had showed histopathological changes in hippocampus (Sharma et al. 2017). Studies have also shown that prenatal and postnatal EMF exposure for $120 \mathrm{~min} /$ day can cause neurodegeneration in the dentate gyrus, hippocampal CA3 region, and increased GFAP (glial fibrillary acidic protein) among astrocytes in offspring and adult animals. These pathological changes may affect memory (Amal et al. 2013). The animals which received $900 \mathrm{MHz}$ RFR for $1 \mathrm{~h}$ /day for 1 week and $1 \mathrm{~h}$ /day for 2 weeks have shown dark neuron in the hippocampus (Awad and Hassan 2008). Animals that were exposed to 25, 50, 75, and 100 missed calls in a day for 4 weeks have shown congestion, hemorrhage, enlarged perivascular spaces, and deformed nuclei. Electron microscopy revealed distorted cristae and swollen mitochondria in neurons of CA3 region of hippocampus. These changes in long term may lead to behavioral and cognitive deficits (Faridi and Khan 2013).

Animals exposed to $1800 \mathrm{MHz}$ RF-EMR from a cell phone for 3 months showed vascular congestion and degenerative changes in pyramidal cells of hippocampus (Hussein et al. 2016). Mice that were exposed to $2 \mathrm{G}$ radiation ( 900 $1800 \mathrm{MHz}$ ) for $48 \mathrm{~min} /$ day for 30-180 days resulted less density of neurons in CA1, CA2 areas of hippocampus; however, CA3 region showed high density of neurons. Further, the nuclear diameter was less in $\mathrm{CA} 1, \mathrm{CA} 2$, and $\mathrm{CA} 3$ region neurons (Mugunthan et al. 2016).

Rats that were exposed to $900 \mathrm{MHz}$ microwaves from 1st to 19 th day of gestation, caused neurodegeneration, and reduced pyramidal cell number in offspring's hippocampus (Bas et al. 2009). Exposure during 13-21 days of pregnancy showed significant loss of pyramidal cells in offspring's hippocampus (Bas et al. 2013). Pregnant animals exposed to $900 \mathrm{MHz}$ radiation $1 \mathrm{~h}$ at a time, three times per day for the period of 21 days showed perivascular edema, chondriosomes in neuron and neuroglia (Gao et al. 2013).

\section{Changes in the cytoarchitecture of cerebral cortex}

Many studies have reported RMF- and EMF-induced histological changes in the cerebral cortex of animals. Significant neuronal damage in cerebral cortex was found following 2-h GSM 900 MHz exposure (Salford et al. 2003). Animals which were exposed to $900 \mathrm{MHz}$ EMR for 1 to 2 weeks have shown dark neurons in the cortex. Adult male Wistar rats that received 900, 1800, and $2450 \mathrm{MHz}$ microwaves about $1 \mathrm{~h}$ /day for the period of 2 months had shown marked degeneration such as contracted cytoplasm and pyknotic nuclei in the frontal cortex neurons (Eser et al. 2013). Rats exposed to $900 \mathrm{MHz}$ radio waves by hand phone for 15 days have also shown neurodegeneration in cerebral cortex (Saikhedkar et al. 2014). A recent report demonstrates that, in neuroinflammatory conditions, acute exposure to GSM$1800 \mathrm{MHz}$ can significantly affect microglia and neuronal activity in the rat primary auditory cortex (Occelli et al. 2018). 


\section{Changes in the cytoarchitecture of cerebellum}

Like other regions of the brain, cerebellum is also vulnerable to RMF exposure. Prenatal ( 0.25 and 11.25 days of gestation till term) exposure to $10 \mathrm{GHz}$ radiation for 15 days in mice showed reduction in Purkinje cell number. (Sharma et al. 2017). Radiation of $900 \mathrm{MHz}$ for 28 days has also resulted in a decrease in Purkinje cell number in female rat cerebellum (Sonmez et al. 2010). Even, $900 \mathrm{MHz}$ EMF for 15 days caused significant Purkinje cell loss. But no significant difference was seen in the number of granular cells (Altun et al. 2017). Rats exposed to cell phone radiation for $30 \mathrm{~min}(2 \mathrm{~h}$ and $8 \mathrm{~h}$ ) showed reduction in internal granular cell population and external granular cell layer thickness (Bolbanabad et al. 2014). Adolescent and young rats from postnatal days 21 to 46 that received $900 \mathrm{MHz}$ RF-EMR for $1 \mathrm{~h} /$ day for 25 days showed fewer Purkinje cells, altered cerebellar morphology (Aslan et al. 2017). Degenerative changes in Purkinje cells of cerebellum have also been noticed in rats exposed to $1800 \mathrm{MHz}$ mobile phone radiation for 3 months (Hussein et al. 2016). However, mice exposed to $900 \mathrm{MHz}$ RF-EMR for 30 days did not show any histopathological changes in the brain (Khalil et al. 2012).

Odaci et al. (2016) exposed pregnant rats from 13 to 21 days of gestation to $900 \mathrm{MHz}$ EMF for $1 \mathrm{~h} /$ day. These rats had shown pyknotic neurons and reduction in total number of Purkinje cells in the offsprings (Odaci et al. 2016). In one of the earlier studies, pregnant Swiss albino mice were subjected to GSM radiation at $890-915 \mathrm{MHz}$. These mice had also shown significant decrease in Purkinje cell number whereas an increased number of granule cells was observed (Ragbetli et al. 2010). In one of the studies, rats from 16 to 21 days of gestation and their young ones were subjected to $100 \mathrm{MHz}$ radiation at $46 \mathrm{~mW} / \mathrm{cm}$ for 97 days. In another study, pregnant rats were irradiated with $2450 \mathrm{MHz}$ continuous microwave at $10 \mathrm{~mW} / \mathrm{cm}^{2} 21 \mathrm{~h} /$ day from 17 to 21 days of gestation. In yet another study, 6-day-old rat pups were exposed to $2450 \mathrm{MHz}$ radiation at $10 \mathrm{~mW} / \mathrm{cm}^{2}$ for 5 days. In both these studies, there was decrease in the number of Purkinje cells in fetal or early post-natal life irradiated animals. Post-natal irradiated animals showed less number of Purkinje cells; however, it was reversible after the recovery period of 40 days (Albert et al. 1981).

\section{Changes in the cytoarchitecture of amygdala}

Studies on changes occurring in the amygdaloid nucleus due to exposure to RF-EMR are scanty. According to a report by Narayanan et al. (2014), on rats, 900 MHz RF-EMR exposure for the period of 4 weeks had resulted in oxidative stress in rat brain. But the magnitude of this varied from one region to the other. Additionally, according to a very recent report, RFEMR exposure $(900 \mathrm{MHz})$ for 28 days had resulted in apoptosis in the amygdala. It had also changed dendritic arborization pattern in basolateral part of amygdala (Narayanan et al. 2018).

\section{Impact of RF-EMR effects on glial cells}

It is now well known that not only neurons but glial cells too help in information processing with regards to animal behavior (Laming et al. 2000; Laming 1989). Hence, poor performance of rats related to behavioral parameters could also be due to the damage to glial cells caused by RF-EMR. This damage, in turn, could alter the neuronal activity in various regions of the brain. Acute exposure to GSM $900 \mathrm{MHz}$ radiation for $15 \mathrm{~min}$ and the glial reaction was evaluated at 2,3,6, and 10 days after exposure. GFAP showed a remarkable increase in frontal cortex, caudate nucleus, cerebellum, and putamen (Brillaud et al. 2007). Chronic exposure to GSM $900 \mathrm{MHz}$ microwaves with SAR of $1.5 \mathrm{~W} / \mathrm{kg}$ for $45 \mathrm{~min} /$ day for 5 days/week for 24 weeks and $15 \mathrm{~min} /$ day at a SAR of $6 \mathrm{~W} / \mathrm{kg}$. Results showed chronic exposure to GSM at $6 \mathrm{~W} /$ $\mathrm{kg}$ increased GFAP-stained areas and astroglia activation in the brain. (Ammari et al. 2008a, b). However, one recent report has shown that long-term exposure of murine brains to $900 \mathrm{MHz}$ RF-EMR at $4 \mathrm{~W} / \mathrm{kg}$, 5 days a week for 104 weeks does not produce any astrogliosis (Court-Kowalski et al. 2015).

\section{Modulatory role of RF-EMR on various neurotransmitter levels in the brain}

RF-EMR exposure can potentially alter the neurotransmitter levels in various brain regions. It is well understood that no brain region works in isolation. Similarly, it is well known that behavioral functions are controlled by the interplay of various brain regions and many neurotransmitters. Therefore, the modulatory effect RF-EMR on various neurotransmitter levels (in various brain regions) is a serious concern. According to many studies, there exists a clear relationship between exposure to RF-EMR and amino acid neurotransmitters imbalance in various parts of the brain of young and adult rats (Noor et al. 2011) and in humans too (Ferreri et al. 2006). A study on fetal rats also indicates that chronic short-term exposure to cell phones can result in marked increase of norepinephrine and dopamine. Moreover, both neurotransmitters were reduced in group that was subjected to radiation for a longer period (Jing et al. 2012). Furthermore, disturbances in the hypothalamic (Radwan et al. 2007), thalamic, and striatal (Ahmed et al. 2007) neurotransmitters after long- and short-term exposure to RF-EMR have been documented earlier. Additionally, it was also found that the RF-EMR can induce changes in the cortical excitability which eventually can lead to changes in cortical amino acid neurotransmitters (Khadrawy et al. 2009). Probably, this might be another reason for behavioral changes found with RF-EMR-exposed rats. 


\section{Possible underlying mechanism for structural changes in the brain after RF-EMR exposure}

As discussed earlier, the structural changes in various brain regions could be one of the main reasons for the behavioral alterations. However, the mechanisms that attribute to altered structures should be considered. It could be the direct effect of radiation on various brain structures or and aftereffect of stress induced by the radiation. A number of mechanisms have been proposed to explain the harmful effects of cell phone RF-EMR on the brain. The effects of RF-EMR on body systems could be thermal effect, non-thermal effect, or cumulative effect. Thermal effect is due to the heating up of the living tissue by rotations of polar molecules induced by the electromagnetic field. Thermal effect is mainly on the superficial structures of the head. Whether it will cause a change in brain function is a subject of debate as calculation of maximum temperature increase on the surface of the head after exposing to mobile phone radiation is found to be only $0.1{ }^{\circ} \mathrm{C}$ (Tahvanainen 2007). A biological effect due to this rise in temperature is a subject to debate. Specific effects (non-thermal effects) of RFEMR are not very well understood. However, the ensuing mechanisms have been postulated to explain these effects on neurons.

\section{Increased generation of reactive oxygen species (ROS)}

Oxygen-free radicals could influence in the mechanisms of the biological effects induced by mobile phone radiation (Narayanan et al. 2014; Phillips and LeDoux 1992; Delullis et al. 2009; Kesari et al. 2012; Alkis et al. 2019). In one of the earlier studies, $900 \mathrm{MHz}$ radiation had increased the serum SOD activity and decreased the serum nitric oxide (NO) in radiation-exposed animals. No change was found in the levels of NO and MDA and activities of adenosine deaminase, xanthine oxidase, catalase, myeloperoxidase, glutathione peroxidase in the serum and brains of either group (Irmak et al. 2002). In a study on guinea pigs, $890-$ to $915-\mathrm{MHz}$ radiation for 30 days had increased the MDA levels. But the glutathione levels and CAT enzyme activity were decreased. Vitamins A, $\mathrm{E}$, and $\mathrm{D}(3)$ levels did not change in the brain tissues of RFEMR-exposed group. Furthermore, increased levels of vitamins A, E, and D(3) levels, MDA, and CAT enzyme activity had increased. Blood GSH level had decreased in RF-EMRexposed group (Meral et al. 2007).

Neurons are largely dependent on oxidative phosphorylation for energy, and this makes them vulnerable for oxidative stress compared to other cells. The metabolic activity of the brain is very high and the demand for oxygen is also high. Approximately $2 \%$ of the oxygen gets converted to hydrogen peroxide and superoxide anion radicals $\left(\mathrm{O}^{2-}\right)$ (de Moura et al. 2010). During RF-EMR exposure, oxidant-antioxidant imbalances in the brain lead to oxidative stress. As a chain reaction, it would have induced structural and later behavioral alterations in rats. Oxidative stress-inducing effect of RF-EMR is a concern due to the following reasons.

a. Interference with the learning and memory processes (Alzoubi et al. 2013).

b. Acceleration in various neurodegenerative diseases (Fridovich 1999).

c. Leading to anxiety-like behaviors (Hovatta et al. 2005).

d. Impairment and oxidization of sugars, proteins, lipids, DNA, consequently leading to malfunction of these molecules within the cells causing their death in various organs (Mohsenzadegan and Mirshafiey 2012).

e. A possible tumor promoter behavior (Kamendulis et al. 1999; Aravalli et al. 2013).

\section{Activation of apoptotic pathway}

Apart from other reasons for cell death in various parts of the brain after the RF-EMR exposure, programmed cell death could be another reason for the same. It has been shown that short-term exposure to radio-frequency emissions (GSM $1900 \mathrm{MHz}$, for $2 \mathrm{~h}$ ) have up-regulated the elements belonging to apoptotic pathways in neurons. The neurons were more sensitive to this effect than the glial cells (Zhao et al. 2007). In one of the studies, cultures of rat neurons were exposed to $900 \mathrm{MHz}$ radiation field. They showed apoptosis with apoptosis-inducing factor (Joubert et al. 2008). But in a study by Maskey et al. (2010a) apoptosis was seen in CA1 and CA3 regions of hippocampus and dentate gyrus of mice. Their study involved several groups with several exposures, which resulted in complete pyramidal neurons in CA1 region of hippocampus in 1 month of exposure group. The authors also suggest that this might affect the cell viability in the hippocampus. Ertilav et al. (2018) have reported that RF-EMR exposure (900 and $1800 \mathrm{MHz}$ ) induced increases in transient receptor potential vanilloid 1 (TRPV1) channel currents, intracellular free calcium influx $\left(\mathrm{Ca}^{2+}\right)$, reactive oxygen species (ROS) production, mitochondrial membrane depolarization (JC-1), apoptosis, and caspase 3 and 9 activities in the hippocampus and dorsal root ganglion of rats. Kesari et al. (2010) have investigated the effect of exposure to $2.45 \mathrm{GHz}$ frequency. In their study, 35-day exposure affected the DNA of rat brain cells. Researchers also reported RF-EMR effects in human cells (Aitken et al. 2005; Tice et al. 2002) and its possible role in programmed cell death (apoptosis). The probable mechanism has been outlined and it shows that the signal transduction processes induce apoptosis in response to DNA damage due to deep penetration of radiation in the brain (Fig. 1). These 


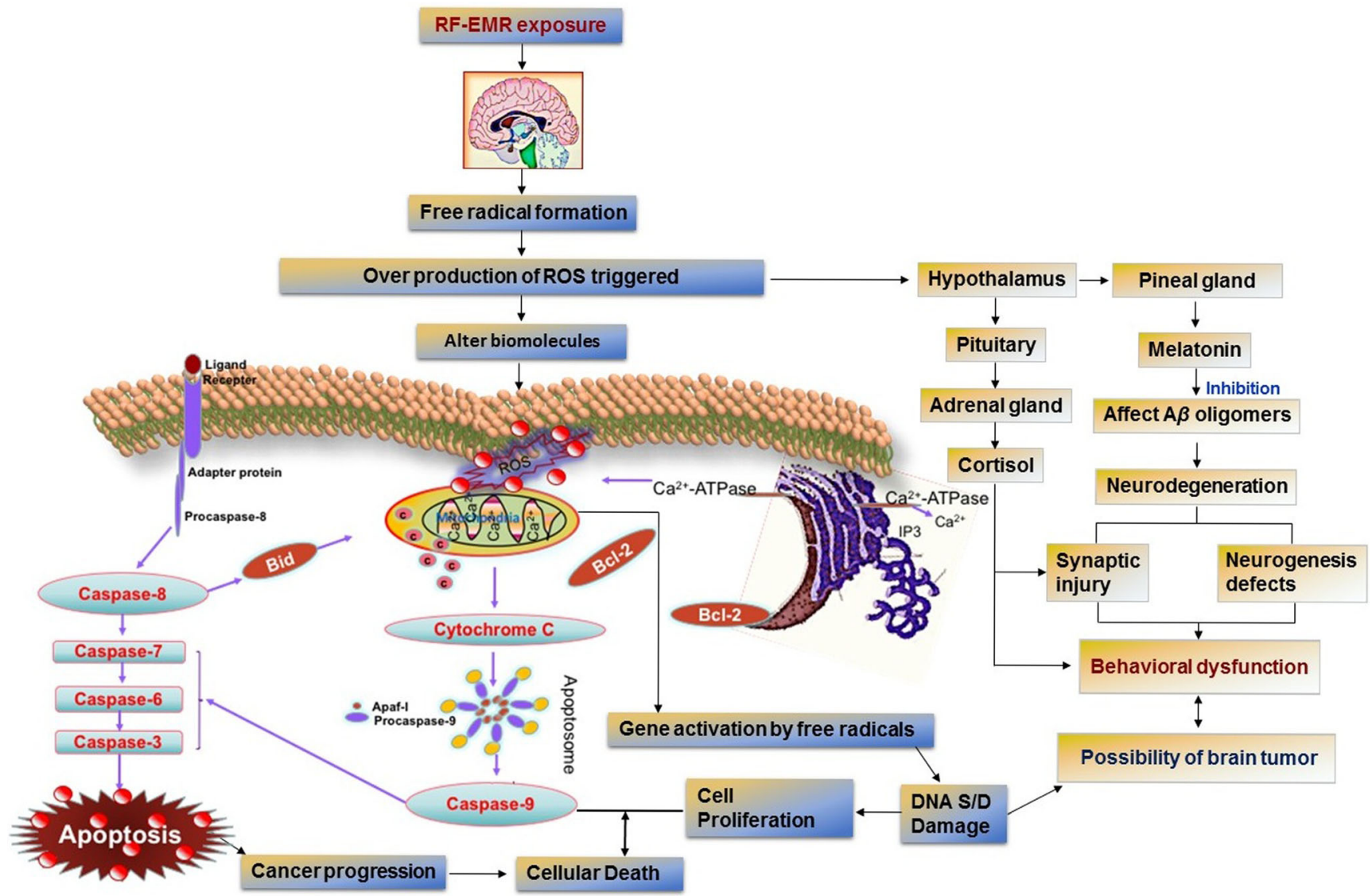

Fig. 1 Possible pathways leading to behavioral dysfunction and other biological effects in the brain following RF-EMR exposure

are mainly attributed to increased ROS generation following RF-EMR exposure.

\section{Effects on DNA}

Evidences suggest that RF-EMR and continuous waves are capable of inducing single-strand DNA breaks (Lai and Singh 1995). A recent study has demonstrated that shortterm exposure (15 and $30 \mathrm{~min}$ ) to $900 \mathrm{MHz}$ RF-EMR from a mobile phone had resulted in remarkable surge in DNA fragmentation in the hair root cells of human situated near the ear, where the phone was placed while making a call (Cam and Seyhan 2012). Another recent report on Japanese Quails demonstrated that exposure to GSM $890-915 \mathrm{MHz}$ RF-EMR markedly changed the number of differentiated somites. In embryos exposed to radiation during intermittent $38 \mathrm{~h}$, there was increase in the number of differentiated somites, while in embryos exposed to radiation during intermittent $158 \mathrm{~h}$, this number had decreased. The exposure for a shorter duration had resulted in a remarkable decrease in the DNA strand breaks in cells of 38-h embryos. But the exposure for higher duration had resulted in an increase in the damage of DNA when compared to the control (Tsybulin et al. 2013).

\section{Effect on calcium influx/efflux across the membrane}

One of the important signaling substances in the cell is calcium and an imbalance in its homeostasis in the cell can alter many functions of the cell. Previous experiments have demonstrated that amplitude-modulated RF electromagnetic fields and low-frequency electric and magnetic fields can influence transport of calcium ions over the cell membrane (Baureus et al. 2003). It was clear that the number of opened calcium channel had increased with the presence of magnetic fields. However, the applied magnetic fields were unable to affect the current of single calcium channel. The increased number of opened calcium channel might be the reason for increased intracellular calcium concentration under RF-EMR exposure (Yu-Hong et al. 2007). Additionally, report indicates that intracellular calcium oscillations can be influenced by extremely low frequency (ELF) magnetic fields which lead to series of cellular responses (Zhao et al. 2008).

The entry of calcium into hippocampal neurons (especially in CA3 neurons) leads to devastating results in CA3 neurons as they are selectively vulnerable to increased intracellular calcium ion concentrations (Sloviter 1989). Increased intracellular calcium disassembles cytoskeletal proteins, especially microtubules (Shankaranarayana Rao et al. 2001). In addition 
to this, increased intracellular calcium causes the dendritic cytoskeleton to depolymerize or undergo proteolysis (Black et al. 1984). In addition, it is proven that changes in intracellular calcium levels can trigger unusual synaptic action or cause neuronal apoptosis. This in turn can exert an influence on learning and memory in the hippocampus (Maskey et al. 2010b). Hippocampal CA3 region of mice exposed chronically to RF-EMR (CDMA $835 \mathrm{MHz}$, electric field strength $59.56 \mathrm{~V} / \mathrm{m}$, power density $2.5 \mathrm{~W}$, and SAR $1.6 \mathrm{~W} / \mathrm{kg}$ ) showed weak calbindin D28-k immunoreactivity (calcium binding protein responsible for maintaining and controlling calcium homeostasis) in the cells of stratum pyramidale and stratum radiatum. Calbindin D28-k immunoreactive neurons displayed morphological changes with loss of dendritic arborization. Decrease of pyramidal cells and loss of D28-k immunoreactivity of mossy fibers were also reported in RF-EMRexposed group (Maskey et al. 2010b). A probable mechanism for atrophy of hippocampal CA3 neurons and associated behavioral changes could be due to RF-EMR-induced impaired calcium homeostasis in CA3 neurons.

\section{A probable combined effect}

Though we narrow down to biochemical imbalance in various brain regions to simplify explanation for structural and behavioral changes, the possibility of combined effects cannot be excluded (Fig. 1). It is also possible that the various behavioral effects the researchers have reported following RF-EMR exposure in animals might be due to combined effects of all that could be happening in various brain regions such as

1. Increase in ROS and thereby cell membrane damage/ integrity.

2. ROS-induced DNA strand break and thereby apoptosis.

3. Imbalance in calcium homeostasis in neurons led to dendritic remodeling/cell death.

4. Increase in ROS-induced inflammation followed by cell death (necrosis).

5. Altered glial cell physiology.

6. Neurotransmitter level imbalance in different brain regions.

Chronic RF-EMR exposure may firstly produce the free radicals in the brain and later they are converted to ROS, which may include oxygen ions, inorganic and organic peroxides. Elevated levels of ROS are capable of attacking various biomolecules in the cell. This raised ROS triggered calcium release may activate the genetic factors and may lead to DNA damage. Perhaps, this is mainly through p53 gene and caspase- 3 activations. Any alteration in gene and enzyme levels, particularly activation of caspase-3 (Liu et al. 2012), may cause apoptosis of neurons (neurodegeneration) which would lead to several altered behavioral manifestations. This neuronal degeneration is a fundamental feature in certain diseases like Parkinson's and Alzheimer's diseases. Reactive oxygen species generated due to exposure to RF-EMR may also react with intracellular DNA and lipoprotein, which may lead to altered cellular function and genotoxic effects (Shahin et al. 2013).

Microwave exposure (2.45-GHz pulsed MW), $3 \mathrm{~h} /$ day up to 30-day induced elevated ROS, may also trigger cognitive dysfunctions by altering the functioning of hypothalamic-pituitaryadrenal (HPA) axis (Li et al. 2008). It may also alter the normal melatonin secretion. In normal concentrations, melatonin scavenges ROS and inhibits the $A \beta$ oligomer-induced toxicity in neurons. Alteration in this would lead to accumulation of $A \beta$ oligomers which would further lead to synaptic injury, cell death, and behavioral dysfunction (Fig. 1). In fact, this seems to be one of the major causes for the disease progression in patients with Alzheimer's disease (AD).

RF-EMR can alter the intracellular signaling pathways like changes in calcium and ionic distribution and also ion permeability at the cellular level (Hossmann and Herman 2003; Adey 1981). It is proposed that RF-EMR exposures alter the calcium channels and receptors on the cell membrane, which play an important role in signaling pathways, which in turn may affect the response of mitochondrial calcium reaction (Walleczek 1992) (Fig. 1).

Fragopoulou et al. (2012) have reported that, RF-EMR exposure triggered the synthesis of 143 proteins, like glial fibrillary acidic protein heat shock protein etc. These change are attributed to the over production of ROS following RF-EMR exposure. It may modify the neuronal proteins and structural components in the brain and participate in various disorders of nervous system, that lead to neuro-inflammation and cognitive impairments. Sharma et al. (2014) have also reported that exposures to RFEMR (10 GHz microwaves, power density $0.25 \mathrm{~mW} / \mathrm{cm}^{2}$, SAR $0.179 \mathrm{~W} / \mathrm{kg}$ for $2 \mathrm{~h} /$ day for 30 days) may reduce the protein levels in the brain. Interestingly, a very recent report demonstrates that GSM irradiation alters amyloid precursor protein (APP) metabolism along with changes in monomeric $\alpha$-syn accumulation, multimerization, oxidative stress, and cell death in cultured $\mathrm{SH}-$ SY5Y cells. The authors have concluded that, GSM radiation seems to contribute to the Alzheimer's and Parkinson's disease pathogenic mechanisms (Stefi et al. 2019). It is apparent from the above discussions that, RF-EMR exposure does increases the formation of ROS and this may alter the cellular functions eventually leading to numerous biological effects (Fig. 1).

\section{Conclusions and scope for future research}

Mobile phone safety recommendations depend mainly on 'sinusoidal wave' emitted from the cell phone when it is idle. At idle mode, the RF-EMR exposure is negligible, hence, it might not be that detrimental at this level. However, chronic 
exposure to the 'carrier signal' emitted when phone is in ' $\mathrm{ON}$ ' mode (when the phone is ringing/call receiving mode) would be responsible for biological effects. Exposure to RF-EMR induces an imbalance in the oxidant/antioxidant defense system in the brain indicating that the internal environment of each brain cell was getting disturbed by the insult from RFEMR. This therefore does not favor the nerve cells to function appropriately. Whenever the threshold is reached, the cell either stops functioning, functions abnormally, or dies. We call it structural change or morphological change. Most of the time, what happens at the cellular level is indicated at the behavioral level. It is highly difficult to join up biochemical change, morphological change, and then behavior. An imbalance in the biochemical homeostasis would itself alter the behavior which might not be structurally represented and vice versa. This is due to the mechanisms, which prevent or resist the insult from external stressors. Currently, we are not sure about this fact as there are no solid evidences which pin point or demonstrate this innate preventive/restrain mechanisms present in neurons under RF-EMR exposure. Further study in this regard will reveal much clearer picture of body's (especially brain) innate mechanisms which would withstand the potential threat caused by RF-EMR.

It is evident from earlier discussions that a possible behavioral effect does exist following RF-EMR exposure in rodents. However, caution should be taken while extrapolating these findings into humans. It is worth noting that an adult uses mobile phone approximately 4 to $5 \mathrm{~h}$ per day and this may be even more in teenagers. However, reports that analyze the behavioral, psychological, and health variables following RFEMR exposure in sensitive population like young adults are scanty. Furthermore, it would be interesting to study the effect of RF-EMR exposure in early developmental stage and see what the effects of such exposures are on the critical and sensitive periods of development using animal models. Although the current review focused principally on RFEMR-induced effects on cognition, anxiety, and locomotion, RF-EMR have been attributed to induce other behavioral effects in rodents as well as in humans. After witnessing the uncontrollable growth of this technology, everyone believes that it is high time to evaluate the health risks of continuous and chronic RF-EMR exposure effects on humans and for which further studies are warranted.

Acknowledgments The authors are grateful to Dr. Sampath Kumar, Chief Librarian \& other library staff of RAK Medical \& Health Sciences University for their support.

Abbreviations $R F-E M R$, Radiofrequency electromagnetic radiation; $I A R C$, International Agency for Research on Cancer; WHO, World Health Organization; $S A R$, Specific absorption rate; $M H z$, Megahertz; $G S M$, Global System for Mobile communication; $B B B$, Blood-brain barrier; $M W M$, Morris water maze; $A \beta$, Amyloid beta; $E P M$, Elevated plus maze; OFT, Open field test; Asp, Spartic acid; EMR, Electromagnetic radiation; CA1, Cornu Ammonis 1; CA2, Cornu Ammonis 2; CA3, Cornu Ammonis 3; $G H z$, Gigahertz; GFAP, Glial fibrillary acidic protein; $G S H$, Glutathione; $M D A$, Malondialdehyde; $P D$, Parkinson's disease; $A D$, Alzheimer's disease; $R F R$, Radiofrequency radiation; $E M F$, Electromagnetic fields; $E M R$, Electromagnetic radiation; GFAP, Glial fibrillary acidic protein; $2 G$, Second generation; $R M F$, Radiomagnetic field; $R F$, Radio frequency; $S O D$, Superoxide dismutase; $N O$, Nitric oxide; $M D A$, Malondialdehyde; GSH, Glutathione; CAT, Catalase; $A I F$, Apoptosis-inducing factor; $D N A$, Deoxyribonucleic acid; $R O S$, Reactive oxygen species; $E L F$, Extremely low frequency; $C D M A$, Code Division Multiple Access; HPA axis, Hypothalamic-pituitary-adrenal axis; TRPV1, Transient receptor potential vanilloid 1 channel; $D E C T$, Digital Enhanced Cordless Telecommunications; $A P P$, Amyloid precursor protein

\section{References}

Adey WR (1981) Ionic nonequilibrium phenomena in tissue interactions with electromagnetic fields. In: Illinger KH (ed) Biological effects of nonionizing radiation Washington. American Chemical Society, DC

Ahmadi S, Alavi SS, Jadidi M, Ardjmand A (2018) Exposure to GSM 900-MHz mobile radiation impaired inhibitory avoidance memory consolidation in rat: involvements of opioidergic and nitrergic systems. Brain Res 1701:36-45. https://doi.org/10.1016/j.brainres. 2018.07.016

Ahmed NA, AboulEzz HS, Khadrawy YA, Radwan NM (2007) Changes of amino acid neurotransmitter concentrations in striatum and thalamus inducedby exposure of young and adult rats to electromagnetic radiation. Med J Cairo Univ 75(suppl):73-84

Aitken RJ, Bennetts LE, Sawyer D, Wiklendt AM, King BV (2005) Impact of radio frequency electromagnetic rad iation on DNA integrity in the male germline. Int J Androl 28:171-9.38

Aksoy U, Sahin S, Ozkoc S, Ergor G (2005) The effect of electromagnetic waves on the growth of Entamoeba histolytica and Entamoeba dispar. Saudi Med J 26(9):1388-1390

Albert EN, Sherif MF, Papadopoulos NJ, Slaby FJ, Monahan J (1981) Effect of nonionizing radiation on the Purkinje cells of the rat cerebellum. Bioelectromagnetics 2(3):247-257

Aldad TS, Gan G, Gao XB, Taylor HS (2012) Fetal radiofrequency radiation exposure from 800-1900 mhz-rated cellular telephones affects neurodevelopment and behavior in mice. Sci Rep 2:312. https://doi. org/10.1038/srep00312

Alkis ME, Bilgin HM, Akpolat V, Dasdag S, Yegin K, Yavas MC, Akdag MZ (2019) Effect of 900-, 1800-, and 2100-MHz radiofrequency radiation on DNA and oxidative stress in brain. Electromagn Biol Med 2019;38(1):32-47. https://doi.org/10.1080/15368378.2019. 1567526

Altun G, Kaplan S, Deniz OG, Kocacan SE, Canan S, Davis D, Marangoz C (2017) Protective effects of melatonin and omega-3 on the hippocampus and the cerebellum of adult Wistar albino rats exposed to electromagnetic fields. J Microsc Ultrastruct 5(4):230 241

Alzoubi KH, Khabour OF, Salah HA, Abu Rashid BE (2013) The combined effect of sleep deprivation and Western diet on spatial learning and memory: role of BDNF and oxidative stress. J Mol Neurosci 50(1):124-133

Amal A, Tolba MA, Omayma K, Afifi A (2013) Histological and Immunohistochemical study onthe effect of mobile phone radiation on the hipocampus of adult and newborn albino rats. Nat Sci 11(8): 98-113

Ammari M, Brillaud E, Gamez C, Lecomte A, Sakly M, Abdelmelek H, de Seze R (2008a) Effect of a chronic GSM $900 \mathrm{MHz}$ exposure on glia in the rat brain. Biomed Pharmacother 62(4):273-281

Ammari M, Jacquet A, Lecomte A, Sakly M, Abdelmelek H, de Seze R (2008b) Effect of head-only sub-chronic and chronic exposure to 
900-MHz GSM electromagnetic fields on spatial memory in rats. Brain Inj 22(13-14):1021-1029

Aravalli RN, Cressman EN, Steer CJ (2013) Cellular and molecular mechanisms of hepatocellular carcinoma: an update. Arch Toxicol 87(2):227-247

Aslan A, İkinci A, Baș O, Sönmez OF, Kaya H, Odacı E (2017) Longterm exposure to a continuous $900 \mathrm{MHz}$ electromagnetic field disrupts cerebellar morphology in young adult male rats. Biotech Histochem 92(5):324-330

Awad SM, Hassan NS (2008) Health risks of electromagnetic radiation from mobile phone on brain of rats. J Appl Sci Res 4(12):1994 1900

Bas O, Odaci E, Mollaoglu H, Ucok K, Kaplan S (2009) Chronic prenatal exposure to the 900 megahertz electromagnetic field induces pyramidal cell loss in the hippocampus of newborn rats. Toxicol Ind Health 25(6):377-384

Bas O, Sönmez OF, Aslan A, Ikinci A, Hanci H, Yildirim M, Kaya H, Akça M, Odaci E (2013) Pyramidal cell loss in the cornuammonis of 32-day-old female rats following exposure to a 900 megahertz electromagnetic field during prenatal days 13-21. Neuro Quantology 11(4):591-599

Baureus Koch CL, Sommarin M, Persson BR, Salford LG, Eberhardt JL (2003) Interaction between weak low frequency magnetic fields and cell membranes. Bioelectromagnetics 24(6):395-402

Black MM, Cochran JM, Kurdyla JT (1984) Solubility properties of neuronal tubulin: evidence for labile and stable microtubules. Brain Res 295(2):255-263

Bolbanabad M, Kaffashian MR, Fatehi D, Rostamzadeh A (2014) Effects of cell phone radiation on migration of granule cells in rat cerebellum. J Bas Res Med Sci 2:15-22

Bornhausen M, Scheingraber H (2000) Prenatal exposure to $900 \mathrm{MHz}$, cell-phone electromagnetic fields had no effect on operant-behavior performances of adult rats. Bioelectromagnetics 21(8):566-574

Bouji M, Lecomte A, Gamez C, Blazy K, Villégier AS (2016) Neurobiological effects of repeated radiofrequency exposures in male senescent rats. Biogerontology 17(5-6):841-857

Bouji M, Lecomte A, Hode Y, de Seze R, Villégier AS (2012) Effects of $900 \mathrm{MHz}$ radiofrequency on corticosterone, emotional memory and neuroinflammation in middle-aged rats. Exp Gerontol 47(6):444 451

Brillaud E, Piotrowski A, de Seze R (2007) Effect of an acute $900 \mathrm{MHz}$ GSM exposure on glia in the rat brain: a time dependent study. Toxicology 238:23-33

Cam ST, Seyhan N (2012) Single-strand DNA breaks in human hair root cells exposed to mobile phone radiation. Int $\mathrm{J}$ Radiat Biol 88(5): 420-424

Cammaerts MC, Rachidi Z, Bellens F, De Doncker P (2013) Food collection and response to pheromones in an ant species exposed to electromagnetic radiation. Electromagn Biol Med 32(3):315-332

Carlberg M, Hardell L (2017). Evaluation of Mobile phone and cordless phone use and glioma risk using the Bradford Hill viewpoints from 1965 on association or causation. Biomed Res Int 9218486. https:// doi.org/10.1155/2017/9218486

Chavdoula ED, Panagopoulos DJ, Margaritis LH (2010) Comparison of biological effects between continuous and intermittent exposure to GSM-900-MHz mobile phone radiation: detection of apoptotic celldeath features. Mutat Res 700(1-2):51-61

Cleveland RF, Ulcek JJL (1999). Questions and answers about biological effects and potential hazards of radiofrequency electromagnetic fields, OET BULLETIN 56, 4th edition, Office of Engineering and Technology Federal Communications Commission; Washington D.C: http://transition.fcc.gov/Bureaus/Engineering Technology/Documents/bulletins/oet56/oet56e4.pdf

Court-Kowalski S, Finnie JW, Manavis J, Blumbergs PC, Helps SC, Vink R (2015) Effect of long-term (2 years) exposure of mouse brains to global system for mobile communication (GSM) radiofrequency fields on astrocytic immunoreactivity. Bioelectromagnetics 36(3): 245-250. https://doi.org/10.1002/bem.21891

Daniels WM, Pitout IL, Afullo TJ, Mabandla MV (2009) The effect of electromagnetic radiation in the mobile phone range on the behaviour of the rat. Metab Brain Dis 24(4):629-641

DeIullis GN, Newey RJ, King BV, Aitken RJ (2009) Mobile phone radiation induces reactive oxygen species production and DNA damage in human spermatozoa in vitro. PLoS One 4:e6446

Eberhardt JL, Persson BR, Brun AE, Salford LG, Malmgren LO (2008) Blood-brain barrier permeability and nerve cell damage in rat brain 14 and 28 days after exposure to microwaves from GSM mobile phones. Electromagn Biol Med 27(3):215-229

Elsawy N, Elkholy S, Azmy R, Maher EA, Shamloul R (2019) Electrophysiological assessment of the impact of Mobile phone radiation on cognition in persons with epilepsy. J Clin Neurophysiol 36(2):112-118. https://doi.org/10.1097/WNP.0000000000000545

Eris AH, Kiziltan HS, Meral I, Genc H, Trabzon M, Seyithanoglu H, Yagci B, Uysal O (2015) Effect of short-term $900 \mathrm{MHz}$ low level electromagnetic radiation exposure on blood serotonin and glutamate levels. Bratisl Lek Listy 116(2):101-103

Ertilav K, Uslusoy F, Ataizi S, Nazıroğlu M (2018) Long term exposure to cell phone frequencies (900 and $1800 \mathrm{MHz}$ ) induces apoptosis, mitochondrial oxidative stress and TRPV1 channel activation in the hippocampus and dorsal root ganglion of rats. Metab Brain Dis 33(3):753-763. https://doi.org/10.1007/s11011-017-0180-4

Eser O, Songur A, Aktas C, Karavelioglu E, Caglar V, Aylak F, Ozguner F, Kanter M (2013) The effect of electromagnetic radiation on the rat brain: an experimental study. Turk Neurosurg 23(6):707-715

Faridi K, Khan AA (2013) Effects of radiofrequency electromagnetic radiations (RF-EMR) on sector CA3 of hippocampus in albino rats-a light and electron-microscopic study. Current Neurobiology 4(1\&2):13-18

Ferreri F, Curcio G, Pasqualetti P, De Gennaro L, Fini R, Rossini PM (2006) Mobile phone emissions and human brain excitability. Ann Neurol 60(2):188-196

Fragopoulou AF, Margaritis LH (2010). Is cognitive function affected by mobile phone radiation exposure? In: Giuliani, L., Soffritti, M. European J. oncology-library, vol. 5 non-thermal effects and mechanisms of interaction between electromagnetic fields and living matter. An ICEMS monograph, (pp. 261-272) Bologna, Italy: Ramazzini institute

Fragopoulou AF, Miltiadous P, Stamatakis A, Stylianopoulou F, Koussoulakos SL, Margaritis LH (2010) Whole body exposure with GSM $900 \mathrm{MHz}$ affects spatial memory in mice. Pathophysiology 17(3):179-187

Fragopoulou AF, Samara A, Antonelou MH, Xanthopoulou A, Papadopoulou A, Vougas K, Koutsogiannopoulou E, Anastasiadou E, Stravopodis DJ, Tsangaris GT, Margaritis LH (2012) Brain proteome response following whole body exposure of mice to mobile phone or wireless DECT base radiation. Electromagn Biol Med 31(4):250-274

Fridovich I (1999) Fundamental aspects of reactive oxygen species, or what's the matter with oxygen? Ann N Y Acad Sci 893:13-8

Gao X, Luo R, Ma B, Wang H, Liu T, Zhang J, Lian Z, Cui X (2013) Interference of vitamin $\mathrm{E}$ on the brain tissue damage by electromagnetic radiation of cell phone in pregnant and fetal rats. Wei Sheng Yan Jiu 42(4):642-646

Gos E, Kohli J, Heyer WD (2000) No mutagenic or recombinogenic effects of mobile phone fields at $900 \mathrm{MHz}$ detected in the yeast saccharomyces cerevisiae. Bioelectromagnetics 21(7):515-523

Hao D, Yang L, Chen S, Tong J, Tian Y, Su B, Wu S, Zeng Y (2013) Effects of long-term electromagnetic field exposure on spatial learning and memory in rats. Neurol Sci 34(2):157-164. https://doi.org/ 10.1007/s10072-012-0970-8

Henz D, Schöllhorn WI, Poeggeler B (2018) Mobile phone chips reduce increases in EEG brain activity induced by Mobile phone-emitted 
electromagnetic fields. Front Neurosci 12:190. https://doi.org/10. 3389/fnins.2018.00190 eCollection 2018

Hossmann KA, Hermann DM (2003) Effects of electromagnetic radiation of mobile phones on the central nervous system. Bioelectromagnetics 24:49-62

Hovatta I, Tennant RS, Helton R, Marr RA, Singer O, Redwine JM, Ellison JA, Schadt EE, Verma IM, Lockhart DJ, Barlow C (2005) Glyoxalase 1 and glutathione reductase 1 regulate anxiety in mice. Nature 438:662-666

Hussein S, El-Saba AA, Galal MK (2016) Biochemical and histological studies on adverse effects of mobile phone radiation on rat's brain. J Chem Neuroanat 78:10-19

IARC (International Agency for Research on Cancer) of World Health Organization (2011). "IARC classifies radiofrequency electromagnetic fields as possibly carcinogenic to humans", press release no 208, 31 May. http://www.iarc.fr/en/media-centre/pr/2011/pdfs/ pr208 E.pdf

Irmak MK, Fadillioglu E, Guleç M, Erdogan H, Yagmurca M, Akyol O (2002) Effects of electromagnetic radiation from a cellular telephone on the oxidant and antioxidant levels in rabbits. Cell Biochem Funct 20(4):279-283

IRWIN FRIDOVICH, (1999) Fundamental Aspects of Reactive Oxygen Species, or What's the Matter with Oxygen?. Annals of the New York Academy of Sciences 893 (1 OXIDATIVE/ENE):13-18

Jing J, Yuhua Z, Xiao-qian Y, Rongping J, Dong-mei G, Xi C (2012) The influence of microwave radiation from cellular phone on fetal rat brain. Electromagn Biol Med 31(1):57-66

Joubert V, Bourthoumieu S, Leveque P, Yardin C (2008) Apoptosis is induced by radiofrequency fields through the caspase-independent mitochondrial pathway in cortical neurons. Radiat Res 169(1):38 45

Junior LC, Guimaraes Eda S, Musso CM, Stabler CT, Garcia RM, Mourao-Junior CA, Andreazzi AE (2014) Behavior and memory evaluation of Wistar rats exposed to $1.8 \mathrm{GHz}$ radiofrequency electromagnetic radiation. Neurol Res 36:800-803

Kai Wang, Jun-Mei Lu, Zhen-He Xing, Qian-Ru Zhao, Lin-Qi Hu, Lei Xue, Jie Zhang, Yan-Ai Mei, (2017) Effect of 1.8 GHz radiofrequency electromagnetic radiation on novel object associative recognition memory in mice. Scientific Reports 7 (1)

Kamendulis LM, Jiang J, Xu Y, Klaunig JE (1999) Induction of oxidative stress and oxidative damage in rat glial cells by acrylonitrile. Carcinogenesis 20(8):1555-1560

Keleș Aİ, Yıldırım M, Gedikli Ö, Çolakoğlu S, Kaya H, Baș O, Sönmez OF, Odac1 E (2018) The effects of a continuous 1-h a day $900-\mathrm{MHz}$ electromagnetic field applied throughout early and mid-adolescence on hippocampus morphology and learning behavior in late adolescent male rats. J Chem Neuroanat 94:46-53. https://doi.org/10. 1016/j.jchemneu.2018.08.006

Kesari KK, Behari J, Kumar S (2010) Mutagenic response of $2.45 \mathrm{GHz}$ radiation exposure on rat brain. Int J Radiat Biol 86:334-343

Kesari KK, Kumar S, Behari J (2012) Evidence for mobile phone radiation exposure effects on reproductive pattern of male rats: role of ROS. Electromagn Biol Med 31:213-222

Khadrawy YA, Ahmed NA, AboulEzz HS, Radwan NM (2009) Effect of electromagnetic radiation from mobile phone on the levels of cortical amino acid neurotransmitters in adult and young rats. Romanian J Biophs 19:295-305

Khalil A, Al-Adhammi M, Al-shara B, Gagaa M, Rawshdeh A, Alshamli A (2012) Histological and ultra-structural analyses of male mice exposed to mobile phone radiation. J of Toxicology Review 1(1): $1-6$

Kim JH, Yu DH, Huh YH, Lee EH, Kim HG, Kim HR (2017) Long-term exposure to $835 \mathrm{MHz}$ RF-EMF induces hyperactivity, autophagy and demyelination in the cortical neurons of mice. Sci Rep 7: 41129. https://doi.org/10.1038/srep41129
Kumar RS, Sareesh NN, Nayak S, Mailankot M (2009) Hypoactivity of Wistar rats exposed to mobile phone on elevated plus maze. Indian J Physiol Pharmacol 53:283-286

Kumlin T, Iivonen H, Miettinen P, Juvonen A, van Groen T, Puranen L, Pitkaaho R, Juutilainen J, Tanila H (2007) Mobile phone radiation and the developing brain: behavioral and morphological effects in juvenile rats. Radiat Res 168(4):471-479

Kuribayashi M, Wang J, Fujiwara O, Nabae K, Tamano S, Ogiso T, Asamoto M, Shirai T (2005) Lack of effects of $1439 \mathrm{MHz}$ electromagnetic near field exposure on the blood-brain barrier in immature and young rats. Bioelectromagnetics 26(7):578-588

Lai H (2014) Neurological effects of non-ionizing electromagnetic fields. Supplement for BioInitiative Working Group

Lai H, Singh NP (1995) Acute low-intensity microwave exposure increases DNA single-strand breaks in rat brain cells. Bioelectromagnetics 16(3):207-210

Laming PR (1989) Do glia contribute to behaviour? A neuromodulatory review. Comp Biochem Physiol A 94:555-568

Laming PR, Kimelberg H, Robinson S, Salm A, Hawrylak N, Müller C et al (2000) Neuronal-glial interactions and behaviour. Neurosci Biobehav Rev 24:295-340

Li M, Wang Y, Zhang Y, Zhou Z, Yu Z (2008) Elevation of plasma corticosterone levels and hippocampal glucocorticoid receptor translocation in rats: a potential mechanism for cognition impairment following chronic low power density microwave exposure. J Radiat Res 49:163-170

Li Y, Shi C, Lu G, Xu Q, Liu S (2012) Effects of electromagnetic radiation on spatial memory and synapses in rat hippocampal CA1. Neural Regen Res 7(16):1248-1255. https://doi.org/10.3969/j.issn. 1673-5374.2012.16.007

Liu B, Jian Z, Li Q, Li K, Wang Z, Liu L, Tang L, Yi X, Wang H, Li C, Gao T (2012) Baicalein protects human melanocytes from $\mathrm{H} 2 \mathrm{O} 2$ induced apoptosis via inhibiting mitochondria-dependent caspase activation and the p38 MAPK pathway. Free Radical Bio Med 53: 183-193

Markkanen A, Penttinen P, Naarala J, Pelkonen J, Sihvonen AP, Juutilainen J (2004) Apoptosis induced by ultraviolet radiation is enhanced by amplitude modulated radiofrequency radiation in mutant yeast cells. Bioelectromagnetics 25(2):127-133

Maskey D, Kim M, Aryal B, Pradhan J, Choi IY, Park KS, Son T, Hong SY, Kim SB, Kim HG, Kim MJ (2010a) Effect of 835 MHz radiofrequency radiation exposure on calcium binding proteins in the hippocampus of the mouse brain. Brain Res 1313:232-241

Maskey D, Pradhan J, Aryal B, Lee CM, Choi IY, Park KS, Kim SB, Kim HG, Kim MJ (2010b) Chronic 835-MHz radiofrequency exposure to mice hippocampus alters the distribution of calbindin and GFAP immunoreactivity. Brain Res 1346:237-246

Masuda H, Hirot S, Ushiyama A, Hirata A, Arima T, Kawai H, Wake K, Watanabe S, Taki M, Nagai A, Ohkubo C (2015) No dynamic changes in blood-brain barrier permeability occur in developing rats during local cortex exposure to microwaves. Vivo 9(3):351-357

Mehmet Esref Alkis, Hakki Murat Bilgin, Veysi Akpolat, Suleyman Dasdag, Korkut Yegin, Mehmet Cihan Yavas, Mehmet Zulkuf Akdag, (2018) Effect of 900-, 1800-, and 2100-MHz radiofrequency radiation on DNA and oxidative stress in brain. Electromagn Biol Med 38 (1):32-47

Meral I, Mert H, Mert N, Deger Y, Yoruk I, Yetkin A, Keskin S (2007) Effects of 900-MHz electromagnetic field emitted from cellular phone on brain oxidative stress and some vitamin levels of Guinea pigs. Brain Res 1169:120-124

Mohsenzadegan M, Mirshafiey A (2012) The immunopathogenic role of reactive oxygen species in Alzheimer disease. Iran J Allergy Asthma Immunol 11(3):203-216

Mokarram P, Sheikhi M, Mortazavi SMJ, Saeb S, Shokrpour N (2017) Effect of Exposure to $900 \mathrm{MHz}$ GSM Mobile Phone Radiofrequency Radiation on Estrogen Receptor Methylation 
Status in Colon Cells of Male Sprague Dawley Rats. J Biomed Phys Eng 7(1):79-86

de Moura MB, dos Santos LS, Van Houten B (2010) Mitochondrial dysfunction in neurodegenerative diseases and cancer. Environ Mol Mutagen 51(5):391-405

Mugunthan N, Shanmugasamy K, Anbalagan J, Rajanarayanan S, Meenachi S (2016) Effects of long term exposure of 900$1800 \mathrm{MHz}$ radiation emitted from $2 \mathrm{G}$ Mobile phone on mice Hippocampus-a Histomorphometric study. J Clin Diagn Res 10(8): AF01-AF06

Narayanan SN, Kumar RS, Potu BK, Nayak S, Mailankot M (2009) Spatial memory performance of Wistar rats exposed to mobile phone. Clinics (Sao Paulo) 64(3):231-234

Narayanan SN, Kumar RS, Potu BK, Nayak S, Bhat PG, Mailankot M (2010) Effect of radio-frequency electromagnetic radiations (RFEMR) on passive avoidance behaviour and hippocampal morphology in Wistar rats. Upsala J Med Sci 115(2):91-96

Narayanan SN, Kumar RS, Paval J, Kedage V, Bhat MS, Nayak S, Bhat PG (2013) Analysis of emotionality and locomotion in radiofrequency electromagnetic radiation exposed rats. Neurol Sci 34: $1117-1124$

Narayanan SN, Kumar RS, Kedage V, Nalini K, Nayak S, Bhat PG (2014) Evaluation of oxidant stress and antioxidant defense in discrete brain regions of rats exposed to $900 \mathrm{MHz}$ radiation. Bratisl Lek Listy 115(5):260-266

Narayanan SN, Kumar RS, Karun KM, Nayak SB, Bhat PG (2015) Possible cause for altered spatial cognition of prepubescent rats exposed to chronic radiofrequency electromagnetic radiation. Metab Brain Dis 30(5):1193-1206. https://doi.org/10.1007/s11011-0159689-6

Narayanan SN, Mohapatra N, John P, K N, Kumar RS, Nayak SB, Bhat PG (2018). Radiofrequency electromagnetic radiation exposure effects on amygdala morphology, place preference behavior and brain caspase-3 activity in rats. Environ Toxicol Pharmacol 58:220-229

Nittby H, Grafström G, Tian DP, Malmgren L, Brun A, Persson BR, Salford LG, Eberhardt J (2008) Cognitive impairment in rats after long-term exposure to GSM-900 mobile phone radiation. Bioelectromagnetics 29(3):219-232

Nittby H, Brun A, Eberhardt J, Malmgren L, Persson BR, Salford LG (2009) Increased blood-brain barrier permeability in mammalian brain 7 days after exposure to the radiation from a GSM-900 mobile phone. Pathophysiology 16(2):103-112

Noor NA, Mohammed HS, Ahmed NA, Radwan NM (2011) Variations in amino acid neurotransmitters in some brain areas of adult and young male albino rats due to exposure to mobile phone radiation. Eur Rev Med PharmacolSci 15(7):729-742

Ntzouni MP, Stamatakis A, Stylianopoulou F, Margaritis LH (2011) Short-term memory in mice is affected by mobile phone radiation. Pathophysiology 18(3):193-199

Obajuluwa AO, Akinyemi AJ, Afolabi OB, Adekoya K, Sanya JO, Ishola AO (2017). Exposure to radio-frequency electromagnetic waves alters acetylcholinesterase gene expression, exploratory and motor coordination-linked behaviour in male rats Toxicol rep 4:30-534

Occelli F, Lameth J, Adenis V, Huetz C, Lévêque P, Jay TM, Edeline JM, Mallat M (2018) A single exposure to GSM-1800 MHz signals in the course of an acute Neuroinflammatory reaction can Alter neuronal responses and microglial morphology in the rat primary auditory cortex. Neuroscience 385:11-24. https://doi.org/10.1016/j. neuroscience. 2018.06.002

Odacı E, İkinci A, Yıldırım M, Kaya H, Akça M, Hancı H, Sönmez O.F, Aslan A, Okuyan M, Baș O (2013). The effects of 900 megahertz electromagnetic field applied in the prenatal period on spinal cord morphology and motor behavior in female rat pups. Neuroquantology 4:573-581

Odaci E, Hanci H, İkinci A, Sönmez OF, Aslan A, Sahin A, Kaya H, Çolakoğlu S, Bas O (2016) Maternal exposure to a continuous 900-
MHz electromagnetic field provokes neuronal loss and pathological changes in cerebellum of 32-day-old female rat offspring. J Chem Neuroanat 75:105-110

Ohl F (2005) Animal models of anxiety. Handb Exp Pharmacol 169:3569

Oscar KJ, Hawkins TD (1977) Microwave alteration of the blood-brain barrier system of rats. Brain Res 126(2):281-293

Phillips RG, LeDoux JE (1992) Differential contribution of amygdala and hippocampus to cued and contextual fear-conditioning. Behav Neurosci 106:274-285

Radwan NM, Ahmed NA, AboulEzz HS (2007) Disturbances in amino acid neurotransmitters induced by mobile phone radiation in the hypothalamus of young and adult albino rats. J Union Arab Biol Cairo 27(A):73-91

Ragbetli MC, Aydinlioglu A, Koyun N, Ragbetli C, Bektas S, Ozdemir S (2010) The effect of mobile phone on the number of Purkinje cells: a stereological study. Int J Radiat Biol 86(7):548-554

Razavinasab M, Moazzami K, Shabani M (2016) Maternal mobile phone exposure alters intrinsic electrophysiological properties of CA1 pyramidal neurons in rat offspring. Toxicol Ind Health 32(6):968-979. https://doi.org/10.1177/0748233714525497

Saikhedkar N, Bhatnagar M, Jain A, Sukhwal P, Sharma C, Jaiswal N (2014) Effects of mobile phone radiation ( $900 \mathrm{MHz}$ radiofrequency) on structure and functions of rat brain. Neurol Res 36(12):10721079. https://doi.org/10.1179/1743132814Y.0000000392

Salford LG, Brun A, Sturesson K, Eberhardt JL, Persson BR (1994) Permeability of the blood-brain barrier induced by $915 \mathrm{MHz}$ electromagnetic radiation, continuous wave and modulated at $8,16,50$, and $200 \mathrm{~Hz}$. Microsc Res Techniq 27(6):535-542

Salford LG, Bru AE, Eberhardt JL, Malmgren L, Persson BR (2003) Nerve cell damage in mammalian brain after exposure to microwaves from GSM mobile phones. Environ Health Perspect 111(7): 881-883

Shahin S, Singh VP, Shukla RK (2013) 2.45 GHz microwave irradiationinduced oxidative stress affects implantation or pregnancy in mice, Mus musculus. Appl Biochem Biotechnol 169:1727-1751

Shankaranarayana Rao BS, Govindaiah LTR, Meti BL, Raju TR (2001) Subicular lesions cause dendritic atrophy in CA1 and CA3 pyramidal neurons of the rat hippocampus. Neuroscience 102(2):319-327

Sharma A, Sisodia R, Bhatnagar D, Saxena VK (2014) Spatial memory and learning performance and its relationship to protein synthesis of Swiss albino mice exposed to $10 \mathrm{GHz}$ microwaves. Int J Radiat Biol 90(1):29-35

Sharma A, Kesari KK, Saxena VK, Sisodia R (2017) The influence of prenatal $10 \mathrm{GHz}$ microwave radiation exposure on a developing mice brain. Gen Physiol Biophys 36(1):41-51

Shehu A, Mohammed A, Magaji RA, Muhammad MS (2016) Exposure to mobile phone electromagnetic field radiation, ringtone and vibration affects anxiety-like behaviour and oxidative stress biomarkers in albino wistar rats. Metab Brain Dis 31:355-362

Sienkiewicz Z, van Rongen E (2019) Can low-level exposure to radiofrequency fields effect cognitive behaviour in laboratory animals? A systematic review of the literature related to spatial learning and place memory. Int J environ res public health. 8:16(9). Pii: E1607. https://doi.org/10.3390/ijerph16091607

Sirav B, Seyhan N (2009) Blood-brain barrier disruption by continuouswave radio frequency radiation. Electromagn Biol Med 28(2):215222

Sloviter RS (1989) Calcium-binding protein (calbindin-D28k) and parvalbumin immunocytochemistry: localization in the rat hippocampus with specific reference to the selective vulnerability of hippocampal neurons to seizure activity. J Comp Neurol 280(2):183196

Sokolovic D, Djordjevic B, Kocic G, Babovic P, Ristic G, Stanojkovic Z, Sokolovic DM, Veljkovic A, Jankovic A, Radovanovic Z (2012) The effect of melatonin on body mass and behaviour of rats during 
an exposure to microwave radiation from mobile phone. Bratisl Lek Listy 113(5):265-269

Son Y, Jeong YJ, Kwon JH, Choi HD, Pack JK, Kim N, Lee YS, Lee HJ (2016) $1950 \mathrm{MHz}$ radiofrequency electromagnetic fields do not aggravate memory deficits in $5 \times$ FAD mice. Bioelectromagnetics 37(6):391-399. https://doi.org/10.1002/bem.21992

Sonmez OF, Odaci E, Bas O, Kaplan S (2010) Purkinje cell number decreases in the adult female rat cerebellum following exposure to $900 \mathrm{MHz}$ electromagnetic field. Brain Res 1356:95-01

Stam R (2010) Electromagnetic fields and the blood-brain barrier. Brain Res Rev 65(1):80-97

Stefi AL, Margaritis LH, Skouroliakou AS, Vassilacopoulou D (2019) Mobile phone electromagnetic radiation affects amyloid precursor protein and $\alpha$-synuclein metabolism in SH-SY5Y cells. Pathophysiology pii S0928-4680(18):30352-30353. https://doi. org/10.1016/j.pathophys.2019.02.004 [Epub ahead of print]

Steimer T (2002) The biology of fear- and anxiety-related behaviors dialogues. Clin Neurosci 4:231-249

Tahvanainen K, Nino J, Halonen P, Kuusela T, Alanko T, Laitinen T, Lansimies E, Hietanen M, Lindholm H (2007) Effects of cellular phone use on ear canal temperature measured by NTC thermistors. Clin Physiol Funct Imaging 27(3):162-172

Tang J, Zhang Y, Yang L, Chen Q, Tan L, Zuo S, Feng H, Chen Z, Zhu G (2015) Exposure to $900 \mathrm{MHz}$ electromagnetic fields activates the mkp-1/ERK pathway and causes blood-brain barrier damage and cognitive impairment in rats. Brain Res 1601:92-101

Tice RR, Hook GG and Donner M (2002) Genotoxicity of radio frequency signals. Investigation of DNA damage and micronuclei induction in cultured human blood cells. Bioelectromagnetics. 23,113-126

Tsybulin O, Sidorik E, Brieieva O, Buchynska L, Kyrylenko S, Henshel D, Yakymenko I (2013) GSM $900 \mathrm{MHz}$ cellular phone radiation can either stimulate or depress early embryogenesis in Japanese quails depending on the duration of exposure. Int J Radiat Biol 89(9):756763

Walleczek J (1992) Electromagnetic field effects on cells of the immune system: the role of calcium signaling. FASEB J 6:3177-3185

Wang K, Lu JM, Xing ZH, Zhao QR, Hu LQ, Xue L, Zhang J, Mei YA (2017) Effect of $1.8 \mathrm{GHz}$ radiofrequency electromagnetic radiation on novel object associative recognition memory in mice. Sci Rep 7: 44521. https://doi.org/10.1038/srep44521

WHO (World Health Organization) (2000). Office of Information.Electromagnetic field and public health: cautionary policies Geneva:World Health Organization http://www.who.int/iris/ handle/10665/57268

WHO (World Health Organization) (2011), "Electromagnetic fields and public health: mobile phones", Fact sheet No193,http://www.who. int/mediacentre/factsheets/fs193/en/

Yu-Hong Z, Yong Z, Tong-Jun Z, Ying-Rong H, Hui L (2007). Mechanism of permeation in calcium channels activation by applied magnetic fields. Conf proc IEEE Eng med biol Soc. 1391-3

Zhang JP, Zhang KY, Guo L, Che QL, Gao P, Wang T, Li J, Guo GZ, Ding GR (2017) Effects of $1.8 \mathrm{GHz}$ radiofrequency fields on the emotional behavior and spatial memory of adolescent mice. Int $\mathrm{J}$ Environ Res Public Health 14:1344

Zhao TY, Zou SP, Knapp PE (2007) Exposure to cell phone radiation upregulates apoptosis genes in primary cultures of neurons and astrocytes. Neurosci Lett 412:34-38

Zhao YL, Yang JC, Zhang YH (2008). Effects of magnetic fields on intracellular calcium oscillations. Conf Proc IEEE Eng Med Biol Soc. $2124-7$

Publisher's note Springer Nature remains neutral with regard to jurisdictional claims in published maps and institutional affiliations. 